barriers and facilitators to intervention uptake and long-term maintenance of required behaviour change.

\section{SOLUTIONS FOR AN AGEING POPULATION FROM EUROPEAN PERSPECTIVE: TECHNOLOGY ENABLED INTEGRATED CARE, IMPLEMENTATION AND UP-SCALING}

Nick Guldemond. Associate Professor Integrated Care and Technology, Senior Policy Advisor, University Medical Centre Utrecht, Executive Board, Concern Staff

\subsection{6/injuryprev-2016-042156.12}

Abstract This presentation provides a holistic perspective on technology enabled integrated care and practical recommendations for implementation and up-scaling: falls prevention and management will illustrate the challenges and opportunities to create a better and safer environment for seniors at risk. Through this example allow people from different backgrounds (from policymakers to work floor carers and patients) to understand the practical implications and benefit of technology enabled integrated care. An integrated fall prevention and management service requires comprehensive coordination of actions in the care and cure as well as the social domain. Historically, there has been little coordination across these sectors. Integrated care may be seen as a response to the fragmented delivery of health and social services. The paradigm shift in healthcare systems also applies to fall prevention and management and comprises a transition: 1) from mainly a monodisciplinary to a multi-disciplinary form of care provision, 2) from a curative approach to preventive medicine and public health, 3) from institutional care to community care, and 4) from professional care to informal care. In the search for effective strategies to prevent and manage fall prevention and management, different models and programs have been proposed. In spite of their differences, all these models or programs aimed at a less fragmented, more integrated provision of patientcentred care. The Integrated Care Model is currently central to European and United States' healthcare policy, and includes important elements of self-management, social support organisations, informal carers and the community. While technology is mentioned as an important facilitator of integrated care, further elaborations on the required functionalities remain absent, as well as the implications of future information and communication technology (ICT) developments. In this presentation, the role of ICT and future developments is discussed from the perspective of integrated falls prevention and management.

\section{ROAD SAFETY: CHALLENGES TO HEALTH SECTOR}

Martha Hijar. General Director of the National Council for Injury Prevention of the Ministry of Health of México, México

\subsection{6/injuryprev-2016-042156.13}

The health of those living in densely populated areas in the world is of interest and concern for two reasons: (1) the large number of people involved, and (2) the fact that the population density of an urban area changes the potential action of Public Health interventions. This is an important issue to be consider on a Road Safety programs.

This paper discusses the need to incorporate the urban issue on its broadest sense related space but geographical size of a city that makes a difference on health terms. The size, density, diversity and especially the complexity of cities impact on mobility and present challenges in public health. Mobility has focused only on ensuring adequate infrastructure and transport services to move passengers and cargo timely, reliable, efficient and sustainable way, as an element essential for economic development. On this regard, the increasing motorization and unsatisfactory modal distribution have created inequality, significant congestion with huge social and environmental costs including negative effects on population health beyond road traffic injuries.

Road safety needs now more than ever, to implement the inter-sectoral work, to assure the links between sectors traditionally separate in language and action. Urban governance might be the best approach to meet the Health sector with all its health challenges including injury prevention, with actors involved in Education, Transport and Development sectors, as well those that ensure the genuine participation of the population.

\section{NEW HORIZONS FOR GLOBAL VIOLENCE PREVENTION}

Alexander Butchart. World Health Organisation, Geneva, Switzerland

\subsection{6/injuryprev-2016-042156.14}

Developments in the global violence prevention field and the surrounding international policy context over the last four to five years have created new windows of opportunity to strengthen science-based approaches to understanding and preventing violence. With a focus on interpersonal violence (i.e. child maltreatment, youth violence, intimate partner violence, sexual violence and elder abuse), this presentation explores the new horizons for global violence prevention that these developments represent.

Within the global violence prevention field, there has been a substantial increase in the number and geographical distribution of nationally representative surveys that document the prevalence, risk factors, and consequences of interpersonal violence, and in particular violence against children and women. Research too has increased, both concerning how exposure to violence can lead to lifelong behavioural, physical and mental health consequences, and by way of outcome evaluation studies into the effectiveness of prevention programmes and victim services. Together, this has resulted in strong convergence between the violence prevention recommendations made by key international and national violence prevention players, and more powerful arguments for investment in evidence-based prevention and response.

Key developments in the international policy context include inclusion in the Sustainable Development Goals of several targets that directly aim at violence prevention, and others that address many of the major underlying causes of violence. Within the health sector, adoption by the May 2016 World Health Assembly of a resolution endorsing the first ever WHO Global plan of action to strengthen the role of the health system in addressing interpersonal violence provides a powerful new incentive for increased health sector involvement in preventing and responding to violence.

In combination, these developments suggest that the next big advances in global violence prevention will entail a stronger emphasis on implementing evidence-based prevention programming and policy at the national and local levels, coupled with a new drive to better measure the nature, reach and quality of evidence-based policies and programmes at national and local levels. Recent examples of initiatives to move global violence prevention efforts in this new direction include the development by WHO and other international agencies of the INSPIRE technical 